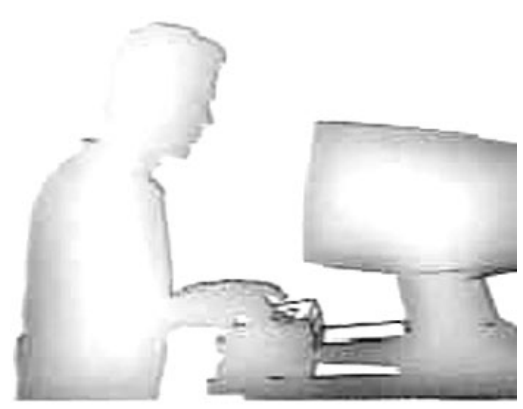

\title{
Modelo de uso da tecnologia de informação no suporte ao processo de ensino-aprendizagem baseado em problemas no curso médico: desenvolvimento e avaliação
}

Model of the use of information technology in providing support for the process of problem-based teaching/learning in medical school: development and evaluation

No contexto das práticas de ensinoaprendizagem, a metodologia da Aprendizagem Baseada em Problemas (PBL Problem-Based Learning) pressupõe um processo centrado no estudante, no qual este seja capaz de aprender por toda vida $e$ trabalhar em grupos a partir de problemas reais. Para seu desenvolvimento o uso da Informática em Saúde é fundamental. O objetivo desta pesquisa foi construir um modelo de uso da tecnologia de informação para o ensino médico e para a busca $e$ recuperação de informações, sobretudo as disponíveis na internet. Os resultados da pesquisa mostraram que os estudantes já iniciam o curso com noções de informática. $\mathrm{Na}$ segunda série, passam a utilizá-la com maior freqüencia do que no ano anterior para buscar informações, trabalho auxiliado pelo treinamento de informática oferecido pela Faculdade. $\mathrm{O}$ método de avaliação dos estudantes quanto à incorporação da informática no cotidiano do trabalhos permitiu identificar pontos que devem ser retrabalhados e mostrou que, de maneira geral, a utilização da tecnologia nas tarefas solicitadas passou de $31 \%$ para $52,4 \%$. O curso e os instrutores foram positivamente avaliados e o modelo proposto atingiu o objetivo, mostrando-se ferramenta eficiente para os estudantes na utilização dos recursos computacionais e da internet na busca $e$ recuperação de informações em um curso que utiliza a metodologia de PBL.

Paulo Marcondes Carvalho Jr. Tese de Doutorado, 2002

Faculdade de Engenharia Elétrica e de Computação, Universidade de Campinas - UNICAMP <paulo@famema.br>

PALAVRAS-CHAVE: Aprendizado baseado em problemas; tecnologia da informação. KEYWORDS: Problem-based learning; information technology.

PALABRAS CLAVE: Aprendizaje basado en problemas; tecnología de la información.

Recebido para publicação em:
Aprovado para publicação em: 20/11/10/02 